levels of activity seemed to have the most adverse effects. Slattery et al found that those who did intense (sporting) activity did not show any more benefit in overall mortality from cardiovascular causes than those who did frequent light or moderate activities but no intense activity.

\section{CONCLUSIONS}

Moderate levels of physical activity, such as frequent regular walking plus recreational activity or sporting activity once a week, seem to be sufficient to produce a significant beneficial effect on cardiovascular risk in men both with and without evidence of ischaemic heart disease or stroke. More vigorous activity does not seem to confer any further protection and frequent sporting (vigorous) activity may be associated with an increased risk of heart attack, especially in those with symptomatic evidence of ischaemic heart disease or stroke. Such men who are contemplating or involved in regular vigorous activity should discuss their programme with an appropriate doctor. It seems reasonable, however, to recommend widespread and unrestricted participation in moderate levels of physical activity. Moderate activity is readily attainable by large sections of the population and requires no special facilities.

This study was supported by The Chest, Heart, and Stroke Association. The British Regional Heart Study is a British Heart Foundation research group and is also supported by the Department of Health and the Institute for Alcoho Studies. We thank Dr Ivan Perry, Dr Peter Whincup, and
Mrs Mary Walker for their comments in preparing this paper.

1 Berlin JA, Colditz A. A meta-analysis of physical activity in the prevention of coronary heart disease. Am f Epidemiol 1990;132:612-27.

2 Shaper AG, Wannamethee G. Physical activity and ischaemic heart disease in middle-aged British men. Br Heart f 1991;66:384-94.

3 Paffenbarger RS, Wing AL. Characteristics in youth predisposing to fatal stroke in later years. Lancet $1967 ; 7: 753-4$.

4 Paffenbarger RS, Brand RJ, Shultz R, Jung D. Energy expenditure, cigarette smoking and blood pressure level as related to death from specific diseases. Am f Epidemiol 1978;108:12-8.

5 Paffenbarger RS, Hyde RT, Wing AL, Steinmetz CH. A natural history of the

6 Herman B, Leyten ACH, van Luijk JH, Frenken CW, Op de Coul AA, Schulte BP. An evaluation of risk factors for stroke in a Dutch community. Stroke 1982;13:334

7 Salonen JT, Puska P, Tuomilehto J. Physical activity and risk of myocardial infarction, cerebral stroke and death. Am f Epidemiol 1982;115:526-31.

8 Shaper AG, Pocock SJ, Walker M, Cohen NM, Wale CJ, Thomson AG British regional heart study: cardiovascular risk factors in middle-aged men in 24 towns. BMJ 1981;283:179-86.

9 Cook DG, Shaper AG, Macfarlane PW. Using the WHO (Rose) angin questionnaire in cardiovascular epidemiological studies. Int $\mathcal{f}$ Epidemio 1989;18:607-13.

10 Wilson PWF, Paffenbarger RS, Morris JN, Havlik RJ. Assessment method for physical activity and physical fitness in population studies: report of NHLBI workshop. Am Heart F 1986;111:1177-92.

11 Taylor HL, Jacobs DR, Schucker B, Knudsen J, Leon AS, Debecker G. A questionnaire for the assessment of leisure time physical activities. A questionnaire for the asse

. Follow-up of subjects in prospective sudies in general practice. $\mathcal{F}$ R Coll Gen Pract 1984;34:365-70

13 Shaper AG, Pocock SJ, Walker M, Phillips AN, Whitehead TP, Macfarlane PW. Risk factors for ischaemic heart disease: the prospective phase of the British regional heart study. $f$ Epidemiol Community Health 1985;39. 197-209.

14 Kannel WB, Sorlie PD. Some health benefits of physical activity. The Framingham study. Arch Intern Med 1979;139:857-61

15 Slattery ML, Jacobs DR, Nichaman MZ. Leisure time physical activity and coronary heart disease death: the US railroad study. Circulation 1989;79. 3104-311.

(Accepted 10 December 1991)
Department of

Epidemiology and

Biostatistics, University of

Limburg, PO Box 616, 6200

MD Maastricht,

Netherlands

Bart W Koes, MA, research

fellow

Lex M Bouter, PHD, associate

professor of epidemiology

Paul G Knipschild, MD

professor of epidemiology

Department of Anatomy and Embryology,

University of Limburg

Henk van Mameren, MD,

associate professor of anatomy

Department of

Physiotherapy, University

Hospital, Maastricht,

Netherlands

Alex H M Essers, PT,

research assistant

Department of

Physiotherapy, Institute of

Higher Education,

Heerlen, Netherlands

Gard M J R Verstegen, PT, practitioner

Jo P Houben, PT, practitioner

Physiotherapy and Manual Therapy Practice,

Maastricht, Netherlands

Domien M Hofhuizen, PT,

practitioner

Correspondence to:

Mr Koes.

BMF 1992;304:601-5

\title{
Randomised clinical trial of manipulative therapy and physiotherapy for persistent back and neck complaints: results of one year follow up
}

\author{
Bart W Koes, Lex M Bouter, Henk van Mameren, Alex H M Essers, Gard M J R Verstegen, \\ Domien M Hofhuizen, Jo P Houben, Paul G Knipschild
}

\section{Abstract}

Objective-To compare the effectiveness of manipulative therapy, physiotherapy, treatment by the general practitioner, and placebo therapy in patients with persistent non-specific back and neck complaints.

Design-Randomised clinical trial.

Setting-Primary health care in the Netherlands.

Patients - 256 patients with non-specific back and neck complaints of at least six weeks' duration who had not received physiotherapy or manipulative therapy in the past two years.

Interventions - At the discretion of the manipulative therapists, physiotherapists, and general practitioners. Physiotherapy consisted of exercises, massage, and physical therapy (heat, electrotherapy, ultrasound, shortwave diathermy). Manipulative therapy consisted of manipulation and mobilisation of the spine. Treatment by general practitioners consisted of drugs (for example, analgesics), advice about posture, home exercises, and (bed)rest. Placebo treatment consisted of detuned shortwave diathermy (10 minutes) and detuned ultrasound (10 minutes).

Main outcome measures-Changes in severity of the main complaint and limitation of physical functioning measured on 10 point scales by a blinded research assistant and global perceived effect measured on a 6 point scale by the patients.

Results - Many patients in the general practitioner and placebo groups received other treatment during follow up. Improvement in the main complaint was larger with manipulative therapy (4.5) than with physiotherapy (3.8) after 12 months' follow up (difference $0.9 ; 95 \%$ confidence interval 0.1 to 1.7 ). Manipulative therapy also gave larger improvements in physical functioning (difference $0.6 ;-0.1$ to 1.3 ). The global perceived effect after six and 12 months' follow up was similar for both treatments.

Conclusions-Manipulative therapy and physiotherapy are better than general practitioner and placebo treatment. Furthermore, manipulative therapy is slightly better than physiotherapy after 12 months.

\section{Introduction}

In most cases of back pain and neck pain no underlying disease can be established and the causes of the complaints remain unknown. ${ }^{12}$ Fortunately, most patients with acute complaints recover within a few weeks, often with the help of (bed)rest, analgesics, and advice about posture and exercises. ${ }^{3}$ The complaints disappear within a few months in about $90 \%$ of the cases, ${ }^{245}$ although the recurrence rate is high. ${ }^{1}$ When the complaints persist there are several options for treatment. General practitioners in the Netherlands often refer patients with persisting complaints for physiotherapy or, less commonly, for manipulative therapy.

Physiotherapists usually give exercise therapy, alone or in combination with other treatments - for example, 
massage, heat, traction, ultrasound, or short wave diathermy. ${ }^{6}$ We know of 16 randomised clinical trials investigating the efficacy of exercises given alone or in combination with additional physical treatments. Unfortunately, most of these studies had severe methodological flaws. Long term positive effects of exercises were reported in only one of the two studies that measured the effect after 12 months. ${ }^{6}$ Despite its widespread use the efficacy of physiotherapy still remains questionable. ${ }^{13-6}$ Most of 35 randomised controlled trials investigating the efficacy of manipulation and mobilisation for back and neck complaints also had severe methodological flaws and gave inconsistent results. ${ }^{7}$ Only seven of the trials measured the effects at least 12 months after randomisation. ${ }^{8.14}$ Long term positive effects favouring manipulation were reported in only one of these studies. ${ }^{9}$

We present the long term results of a randomised clinical trial comparing manipulative therapy, physiotherapy, treatment by the general practitioner, and a placebo treatment for patients with persistent back and neck complaints. The design of the study ${ }^{15}$ and its short term results are reported in detail elsewhere. ${ }^{16} 17$

\section{Subjects and methods}

\section{SELECTION OF PATIENTS}

Patients who had had back and neck pain for at least six weeks were selected by general practitioners and by advertisements in the local press over two years (January 1988-December 1989). Subsequently, all potential participants were seen by the same research assistant (an experienced physiotherapist and manua therapist), who performed a physical examination and did the final check with respect to the admission criteria. ${ }^{15}$ Patients had to meet the following criteria: the complaint was non-specific - that is, no underlying disease could be established (for example, malignity, osteoporosis, herniated disc); the duration of the complaint was six weeks or longer; no physiotherapy or manipulative therapy for back and neck complaints had been received in the past two years; and the complaint could be reproduced by active or passive physical examination.

The purpose of these criteria was to select a (relatively) homogeneous group of patients suitable for treatment with physiotherapy, manipulative therapy, and continued care by the general practitioner. Eligible patients gave informed consent by signing a letter. Subsequently, randomisation was carried out by a second research assistant using a list of random numbers.

\section{TREATMENTS}

Four treatments were included in the trial. Firstly, physiotherapy, which consisted of exercises, massage and/or physical therapy modalities (heat, electrotherapy, ultrasound, shortwave diathermy). Secondly, manipulative therapy, which consisted of manipulative techniques (manipulation and mobilisation of the spine) included in the directives of the Dutch Society for Manual Therapy (NVMT). (The manual therapists were all physiotherapists with an additional three to four years' education in manipulation.) Thirdly, continued treatment by the general practitioner, which consisted of prescribed drugs (for example, analgesics, non-steroidal anti-inflammatory drugs), advice about posture, home exercises, participation in sports, (bed)rest, etc. Fourthly, placebo treatment, which in each session consisted of a physical examination and then detuned shortwave diathermy (10 minutes) and detuned ultrasound (10 minutes) carried out by the participating physiotherapists. The placebo treatment sessions were scheduled twice a week for six weeks.

All therapists (except for those giving placebo treat- ment) were free to choose from their usual therapeutic domain within some explicitly formulated limits (for example, no manipulative techniques could be performed by the physiotherapists). All treatments were given for a maximum of three months.

\section{OUTCOME MEASURES}

Follow up measurements were carried out at six and 12 months after randomisation in order to study long term effects. Below, we focus on the three outcome measures which proved sensitive in measuring changes at the short term follow up (three, six, and 12 weeks after randomisation $)^{16}{ }^{17}$ : severity of the main complaint, global perceived effect, and physical functioning.

The main complaint was determined as the complaint which the patient considered to be the most important at baseline. Its severity was assessed by the research assistant on a 10 point scale $(1=$ minimal severity, $10=$ maximal severity) based on history taking and physical examination. During all follow up measurements the research assistant was unaware of the treatment to which the patients were assigned. He also had no information about the previous scores. Global perceived effect was assessed by the patients on a 6 point scale ( $1=$ no benefit, $6=$ maximal benefit $)$ after six and 12 months' follow up. Physical functioning was measured by the ability of patients to perform active spinal movements. Patients with neck complaints were asked to perform a standardised set of cervical movements (anteflexion, retroflexion, lateroflexion, and rotation); those with back complaints had to perform a similar set of trunk movements. At baseline the research assistant noted for each patient the movements (maximum of three) for which the patient reported the most severe pain or limitation of the range of motion. In addition, the severity of the pain (or of the limitation of range of motion) for these movements was scored on a 10 point scale $(1=$ minimal severity, $10=$ maximal severity). At follow up the movements chosen at baseline were reassessed by the same (blinded) research assistant, who was unaware of the previous scores. The physical functioning score was calculated by adding the severity scores of all (maximum of three) movements at issue divided by the number of movements. ${ }^{17}$

\section{STATISTICAL ANALYSIS}

The cumulative number of patients in each of the four treatment groups who had deviated from the allocated treatment after six and 12 months' follow up was calculated. The effects in the group receiving placebo therapy and the group receiving treatment by the general practitioner seemed to be seriously biased owing to contamination and cointerventions (see results). Therefore, we restricted the data analysis for the three outcome measures to the manipulative therapy and physiotherapy groups only.

For two outcome measures (severity of the main complaint and physical functioning) we calculated the differences between the follow up scores and the baseline score for individual patients. Subsequently, the two study groups were compared with each other for their imnrovement 12 months after randomisation The global perceived effect at six and 12 months was also compared. In addition, we calculated the cumulative distributions of the improvement scores for the severity of the main complaint and for physical functioning and global perceived effect at 12 months' follow up. Group differences and $95 \%$ confidence intervals after six and 12 months' follow up were calculated for the three outcome measures with a linear regression model in order to estimate differences between groups after adjusting for small imbalances in important prognostic indicators at baseline. In the model we entered the following covariables: location 


\begin{tabular}{|c|c|c|c|c|c|}
\hline Characteristic & $\begin{array}{l}\text { Manipulative } \\
\text { therapy }\end{array}$ & Physiotherapy & $\begin{array}{l}\text { Placebo } \\
\text { therapy }\end{array}$ & $\begin{array}{c}\text { General } \\
\text { practitioner }\end{array}$ & $\begin{array}{c}\text { All } \\
\text { subjects }\end{array}$ \\
\hline Total No of subjects & 65 & 66 & 64 & 61 & 256 \\
\hline No (\%) selected through advertisement & $49(75)$ & $42(64)$ & $44(69)$ & $38(62)$ & $173(68)$ \\
\hline Mean age (years) & & & & 43 & 43 \\
\hline $\operatorname{Sex}(\mathrm{No}(\%)$ female $)$ & $35(54)$ & $32(48)$ & $33(52)$ & $23(38)$ & $123(48)$ \\
\hline \multicolumn{6}{|l|}{ Location of complaints $(\mathrm{No}(\%))$ : } \\
\hline Back & $36(55)$ & $36(54)$ & $40(62)$ & $32(53)$ & $144(56)$ \\
\hline Neck & $13(20)$ & $21(32)$ & $14(22)$ & $16(26)$ & $64(25)$ \\
\hline Back and neck & $16(25)$ & $9(14)$ & $10(16)$ & $13(21)$ & $48(19)$ \\
\hline \multicolumn{6}{|c|}{ Median duration of present episode of complaints (weeks): } \\
\hline Patients with back or neck complaints $(n=208)$ & 52 & 52 & 52 & 45 & 52 \\
\hline \multicolumn{6}{|l|}{ Patients with back and neck complaints $(n=48)$ : } \\
\hline Back & 78 & 26 & 92 & 78 & 79 \\
\hline Neck & 91 & 26 & 65 & 52 & 52 \\
\hline \multicolumn{6}{|l|}{ No $(\%)$ who had had previous treatment: } \\
\hline Physiotherapy & $38(58)$ & $30(45)$ & $37(58)$ & $49(48)$ & $134(52)$ \\
\hline Manipulative therapy & $8(12)$ & $12(18)$ & $3(5)$ & $6(10)$ & $29(11)$ \\
\hline Alternative medicine & 9(14) & $12(18)$ & $6(9)$ & $12(20)$ & $39(15)$ \\
\hline Specialist & $11(17)$ & $12(18)$ & $14(22)$ & $11(18)$ & $48(19)$ \\
\hline Mean severity of main complaint ( 10 point scale $)$ & $7 \cdot 0$ & $7 \cdot 0$ & 6.8 & 6.8 & 6.9 \\
\hline Mean physical functioning score (10 point scale) & 5.9 & $5 \cdot 8$ & $5 \cdot 7$ & $5 \cdot 7$ & 5.8 \\
\hline
\end{tabular}

and duration of the main complaint, the baseline score of the outcome measure at issue (except for global perceived effect in which case severity of the main complaint at baseline was chosen), age, and recruitment status (general practitioner or advertisement). We also calculated the power of the study based on the results for severity of main complaint after 12 months' follow up (see appendix). The analyses were carried out with the biomedical programs data package, 1990 version. ${ }^{18}$

\section{Results}

A total of 256 patients met the inclusion criteria and were randomly assigned to the four treatments. Table I shows the demographic and clinical characteristics of the participants. Comparability between the four groups for the main prognostic variables such as duration, severity, and location of the complaints and age was satisfactory. The median duration of the episode of back or neck pain for all patients was 52 weeks, indicating that most patients had very long

TABLE II-Mean (median) number of treatments, length of session, and duration of treatment during the intervention period

\begin{tabular}{|c|c|c|c|}
\hline & $\begin{array}{l}\text { No of } \\
\text { treatments }\end{array}$ & $\begin{array}{l}\text { Length of } \\
\text { session } \\
\text { (min) }\end{array}$ & $\begin{array}{l}\text { Duration of } \\
\text { treatment } \\
\text { (weeks) }\end{array}$ \\
\hline $\begin{array}{l}\text { Manipulative therapy } \\
\text { Physiotherapy } \\
\text { Placebo therapy } \\
\text { General practitioner }\end{array}$ & $\begin{array}{r}5 \cdot 4(6) \\
14 \cdot 7(14) \\
11 \cdot 1(12)\end{array}$ & $\begin{array}{l}41(40) \\
35(30) \\
29(30)\end{array}$ & $\begin{array}{l}8.9(9) \\
7.8(8) \\
5.8(6)\end{array}$ \\
\hline
\end{tabular}

Treatment by the general practitioner consisted usually of a single visit by the patient at the general practice.

TABLE III-Cumulative number of deviations from the allocated therapy at follow up

\begin{tabular}{|c|c|c|}
\hline Treatment group & 6 Month follow up & 12 Month follow up \\
\hline Manipulative therapy & $\begin{array}{l}3 \text { Physiotherapy } \\
2 \text { Specialist } \\
1 \text { Operation for herniated nucleus polposus } \\
1 \text { Injection } \\
1 \text { Alternative medicine }\end{array}$ & $\begin{array}{l}5 \text { Physiotherapy } \\
2 \text { Specialist } \\
1 \text { Operation for herniated nucleus polposus } \\
1 \text { Injection } \\
2 \text { Alternative medicine }\end{array}$ \\
\hline Physiotherapy & $\begin{array}{l}2 \text { Manual therapy } \\
1 \text { Sport massage } \\
1 \text { Specialist } \\
1 \text { Alternative medicine }\end{array}$ & $\begin{array}{l}6 \text { Manual therapy } \\
1 \text { Sport massage } \\
7 \text { Specialist } \\
2 \text { Alternative medicine }\end{array}$ \\
\hline Placebo therapy & $\begin{array}{l}18 \text { Physiotherapy } \\
3 \text { Manual therapy } \\
1 \text { Cesar therapy } \\
2 \text { Specialist } \\
1 \text { Operation for herniated nucleus polposus }\end{array}$ & $\begin{array}{l}19 \text { Physiotherapy } \\
3 \text { Manual therapy } \\
1 \text { Cesar therapy } \\
5 \text { Specialist } \\
1 \text { Operation for herniated nucleus polposus }\end{array}$ \\
\hline General practitioner & $\begin{array}{l}8 \text { Physiotherapy } \\
6 \text { Manual therapy } \\
2 \text { Cesar therapy } \\
1 \text { Sport massage } \\
2 \text { Specialist } \\
1 \text { Operation for herniated nucleus polposus } \\
1 \text { Hospital admission } \\
2 \text { Alternative medicine }\end{array}$ & $\begin{array}{l}12 \text { Physiotherapy } \\
6 \text { Manual therapy } \\
2 \text { Cesar therapy } \\
1 \text { Sport massage } \\
2 \text { Specialist } \\
1 \text { Operation for herniated nucleus polposus } \\
1 \text { Hospital admission } \\
2 \text { Alternative medicine }\end{array}$ \\
\hline
\end{tabular}

periods of back or neck pain. About half the patients had previously received physiotherapy for their complaints (but not during the two years before entering the trial).

Table II shows the number of treatments, length of sessions, and duration of treatment for the four study groups. The manual therapy group had fewer treatments than the physiotherapy group (mean $5 \cdot 4 v 14 \cdot 7$ ). Patients in the general practitioner group mostly paid only one visit to their general practitioner.

Table III presents the cumulative number of the deviations from the allocated therapy at follow up after six and 12 months. Contamination and cointerventions mainly occurred among patients in the placebo and general practitioner groups.

In addition, there were three patients in the physiotherapy group and nine patients in the manipulative therapy group who continued their allocated treatment after the planned maximum of three months. Four patients in the physiotherapy group and three patients in the manipulative therapy group started a new period of the allocated treatment. Overall, the number of deviations from the study protocol among patients receiving manipulative therapy or physiotherapy seemed equally distributed.

After six month's follow up $11(17 \%)$ patients in the physiotherapy group and seven (11\%) patients in the manipulative therapy group did not fill out the written questionnaire. After 12 months' follow up $17(26 \%)$ patients in the physiotherapy group and $10(15 \%)$ patients in the manipulative therapy group did not attend for the final assessment of effect (change in main complaint and physical functioning) by the research assistant. However, after 12 months' follow up most patients filled out the questionnaire: only six (9\%) patients who received physiotherapy and five $(8 \%)$ who received manipulative therapy could not be persuaded to do so. Table IV lists the results up to 12 months' follow up for the manipulative therapy and physiotherapy groups. With regard to the change of the main complaint, the manipulative therapy group showed the largest improvement (4.5 (SD 2.2)) after 12 months' follow up. The difference in improvement scores between both groups was 0.9 (95\% confidence interval $0 \cdot 1$ to $1 \cdot 7$ ). The manipulative therapy group showed consistently better results for physical functioning than the physiotherapy group at all follow up measurements. The difference between both groups after 12 months' follow up was $0 \cdot 6(-0 \cdot 1$ to $1 \cdot 3)$. For global perceived effect, both groups showed similar results at all follow up measurements.

Even among patients assigned to manipulative therapy and physiotherapy there was a considerable number of missing values at 12 months' follow up Therefore, we also conducted an alternative analysis, 


\begin{tabular}{|c|c|c|c|c|c|c|}
\hline Outcome measure & 3 Weeks & 6 Weeks & 12 Weeks & 6 Months & 12 Months & $\begin{array}{c}\text { Difference ( } 95 \% \text { confidence interval) } \\
\text { between manipulative therapy and } \\
\text { physiotherapy groups }{ }^{\star}\end{array}$ \\
\hline \multicolumn{7}{|c|}{ Mean (SD) improvement in main complaint ( 10 point scale): } \\
\hline Manipulative therapy & $2 \cdot 3(2 \cdot 1)$ & $3 \cdot 4(2 \cdot 1)$ & $4 \cdot 0(2 \cdot 6)$ & & $4 \cdot 5(2 \cdot 2)$ & $0.9(0.1$ to 1.7$)$ at $12 \mathrm{months}$ \\
\hline Physiotherapy & $2 \cdot 0(2 \cdot 3)$ & $3 \cdot 4(2 \cdot 4)$ & $3 \cdot 8(2 \cdot 3)$ & & $3 \cdot 8(2 \cdot 3)$ & \\
\hline \multicolumn{7}{|c|}{ Mean (SD) global perceived effect ( 6 point scale): } \\
\hline Manipulative therapy & $2 \cdot 5(1 \cdot 5)$ & $3 \cdot 4(1 \cdot 7)$ & $3 \cdot 4(2 \cdot 0)$ & $3 \cdot 5(1 \cdot 9)$ & $3 \cdot 5(1 \cdot 8)$ & $0 \cdot 3(-0.4$ to $1 \cdot 0)$ at 6 months \\
\hline Physiotherapy & $2 \cdot 6(1 \cdot 6)$ & $3 \cdot 3(1 \cdot 6)$ & $3 \cdot 7(1 \cdot 7)$ & $3.5(1.8)$ & $3 \cdot 2(1.9)$ & $0.4(-0.3$ to 1.4$)$ at 12 months \\
\hline \multicolumn{7}{|c|}{ Mean (SD) improvement in physical functioning ( 10 point scale): } \\
\hline Manipulative therapy & $2 \cdot 3(2 \cdot 1)$ & $3 \cdot 5(1.9)$ & $4 \cdot 0(2 \cdot 3)$ & & $4 \cdot 2(2 \cdot 1)$ & $0.6(-0.1$ to 1.3$)$ at 12 months \\
\hline Physiotherapy & $1 \cdot 6(1 \cdot 9)$ & $3 \cdot 1(1 \cdot 8)$ & $3 \cdot 2(2 \cdot 0)$ & & $3 \cdot 7(2 \cdot 0)$ & \\
\hline
\end{tabular}

^The group differences ( $95 \%$ confidence intervals) were calculated with a linear regression model.

in which we substituted the last measurement available for missing values. The results of this analysis showed slightly smaller improvement scores for both groups. The mean (SD) improvement for the main complaint after 12 months in this alternative analysis was $4 \cdot 1(2 \cdot 4)$ for manipulative therapy and $3.4(2.7)$ for physiotherapy. The group difference was $0 \cdot 9(0 \cdot 1$ to $1 \cdot 8)$. The mean (SD) improvement for the physical functioning was $3 \cdot 8(2 \cdot 3)$ for manipulative therapy and $3 \cdot 1(2 \cdot 2)$ for physiotherapy. The group difference was $0.8(0 \cdot 1$ to $1 \cdot 5)$. Both differences were significant at the $5 \%$ level.

Figure 1 shows the cumulative distribution of the improvement score for the main complaint in the groups that received manipulative therapy or physiotherapy. For any cut off point the proportion of patients in both study groups with at least that score can be read on the ordinate. For example, $75 \%$ in the manipulative therapy group and $65 \%$ in the physiotherapy group showed an improvement score of 3 points or more at 12 months' follow up. Manipulative therapy showed the best outcome for improvement scores of 7 points or less. Figure 2 gives the cumulative distribution of the global perceived effect at 12 months' follow up. The cumulative distributions of both groups were similar. Only for the benefit scores of 3 and 4 was the proportion of patients with at least that score higher among patients receiving manipulative

FIG 1-Cumulative distribution of improvement in score for main complaint after 12 months' follow up in patients given manipulative therapy and physiotherapy
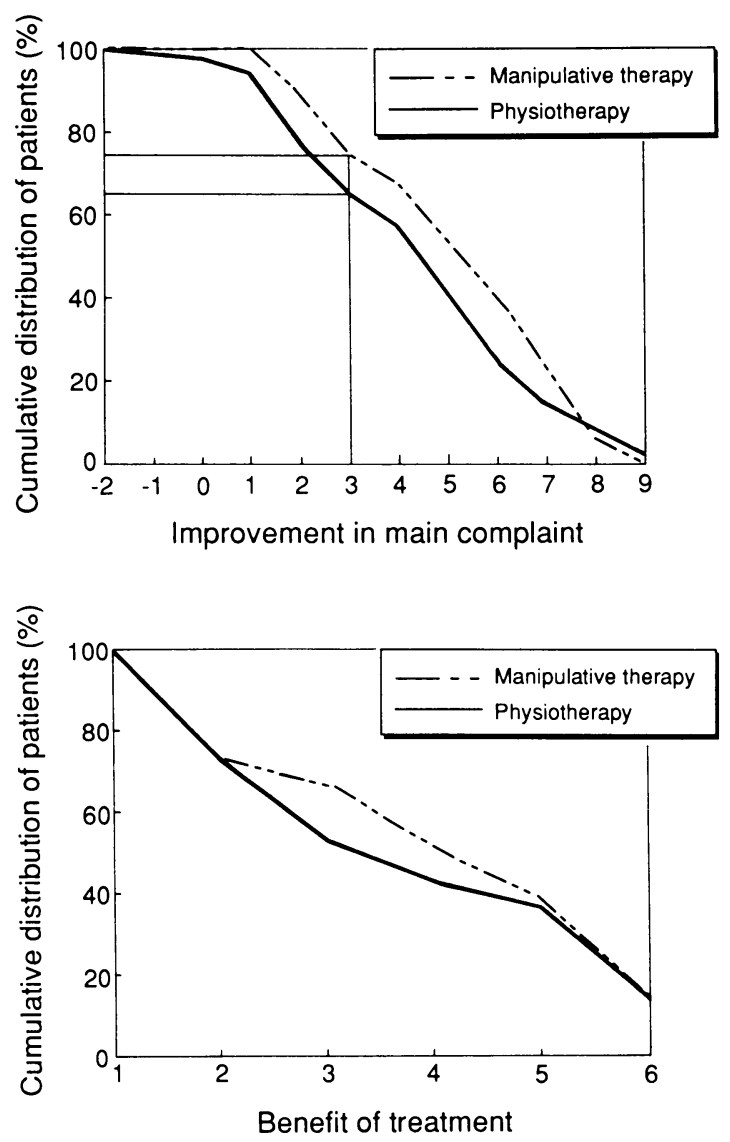

therapy. Figure 3 gives the cumulative distribution of the improvement scores for physical functioning after 12 months' follow up. For any improvement score the proportion of patients with at least that score was higher among patients who received manipulative therapy than among those who received physiotherapy.

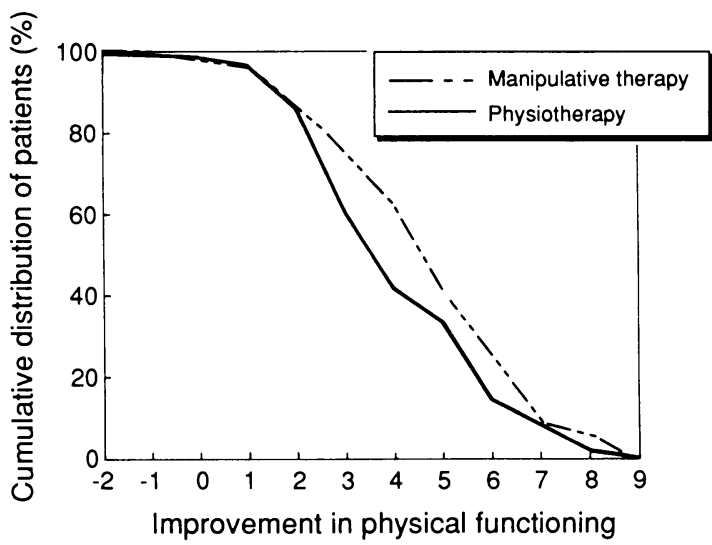

FIG 3-Cumulative distribution of improvement in score for physical functioning after 12 months' follow up in patients given manipulative therapy and physiotherapy

\section{Discussion}

A large number of patients changed from the assigned treatment to another treatment during the one year follow up in the placebo and general practitioner groups. A change in treatment was not chosen as an outcome measure when the trial was designed, but this outcome clearly indicates the superiority of both manipulative therapy and physiotherapy over the two other treatments. The underlying assumption is that patients will in general turn to other treatments when the allocated treatment is not effective enough.

Because of the large numbers of deviations from the allocated treatment in the placebo and general practitioner groups after six and 12 months' follow up we expected serious bias due to contamination and $\mathrm{co}^{-}$ interventions. We therefore decided not to analyse the data on the outcome measures at these follow up measurements.

It might have been possible to perform a pragmatic analysis on the collected data. In retrospect, we would have classified the four study groups according to the treatment they actually received instead of the treat ment they were originally assigned to. For methodological reasons, however, we decided not to perform such analysis because it would almost certainly bias outcomes. The main problem would be that the prognosis of patients who deviated from the assigned therapy would be different from that of those who did not. In fact, in a pragmatic analysis all the advantages of randomisation aiming at prognostic comparability of the study groups at baseline would be lost. Instead of an experimental design we would have been left with an observational study.

The comparison between manipulative therapy and
2-Cumulative distribution of score for global perceived effect after 12 months' follow up in patients given manipulative therapy and physiotherapy 
physiotherapy at six and 12 months' follow up remained valid and relevant. The short term results had shown similar success rates in both these groups, ${ }^{16}{ }^{17}$ but long term effects are also important for patients with persistent back and neck complaints. After 12 months manipulative therapy had produced a larger mean improvement in the main complaint than physiotherapy. This pattern was also shown in the cumulative distributions of the improvement scores for the main complaint of both groups (fig 1). The difference between both groups was significant. Physical functioning also seemed to improve consistently more with manipulative therapy, but the difference was not significant after 12 months' follow up. For the global perceived effect we could not find any substantial difference between both therapies. At six months' follow up both groups showed equal scores (3.5 points). At 12 months' follow up the manipulative therapy group scored slightly higher than the physiotherapy group ( $3.5 v 3.2$ points). The cumulative distributions showed some difference in favour of manipulative therapy only for benefit scores of 3 and 4 points. However, the $95 \%$ confidence interval for the group difference was -0.3 to 1.4 .

It is remarkable that the patients in the manipulative therapy group showed better results compared with those in the physiotherapy group at 12 months' follow up. Long term benefits of manipulative therapy are seldomly reported. ${ }^{7}$ The patients in the manipulative therapy group showed the highest improvement in scores at 12 months, while for most patients the time of greatest improvement was about nine months after the last treatment session. There are several explanations for this finding.

Firstly, it might be that the relatively large number of missing values after 12 months represent those who responded badly to treatment. The patients who did attend for the follow up assessment might therefore be a selected group of patients in whom the therapy was successful. In our alternative analysis, however, we substituted the last available measurement for missing values, and this did not change the results appreciably. Furthermore, the number of missing values was larger in the physiotherapy group (26\%) than in the manipulative therapy group $(15 \%)$. We therefore think that missing values cannot explain our findings.

Secondly, many patients might have received additional manipulative therapy or other cointerventions during the nine months after the intervention period. Table III shows that several patients did receive additional treatment, but the numbers were comparable with those in the physiotherapy group. Thirdly, it might be that the blinding of the research assistant was not fully successful. Although we did not measure the success of blinding explicitly, we have no reason to believe that it failed. Finally, manipulative therapy may help to restore the function of the spine better than physiotherapy. In the case of persistent conditions a relatively long period might be needed to achieve maximal reduction of the complaints. A physiological explanation for such a mechanism has not yet been shown. The few earlier studies which had included a long term follow up mostly did not report long term positive results of manipulation. ${ }^{80-14}$ There is one study in which the authors report long term benefit of manipulation for chronic or severe pain, especially at longer term (two years) follow up. In this large multicentre trial chiropractic manipulation was compared with (physiotherapeutic) hospital outpatient treatment for low back pain. ${ }^{9}$ An important extra finding was that the number of treatments was much lower for manipulative therapy than physiotherapy. This might be regarded as a considerable advantage.

We conclude that after 12 months' follow up both manipulative therapy and physiotherapy seem to be more effective than treatment by the general practitioner or placebo treatment in patients with persistent back and neck pain. Furthermore, the findings indicate a slightly better result from manipulative therapy compared with physiotherapy after 12 months' follow up. Further trials of manipulation are needed to determine its long term effects in patients with more specific conditions.

We thank Monique Latour for her help in conducting this study. This study was funded by the Dutch Ministry of Welfare, Health, and Cultural Affairs and by the Dutch National Health Insurance Council.

1 Frymoyer JW. Back pain and sciatica. N Engl f Med 1988;318:291-300.

2 Waddell G. A new clinical model for the treatment of low-back pain. Spine 1987;12:632-44.

Nachemson A. A critical look at the treatment for low back pain Scand F Rehab Med 1979;11:143-7.

4 Deyo RA. Conservative therapy for low back pain. FAMA 1983;250:1057-62.

5 Spitzer WO, Leblanc FE, Dupuis M. Scientific approach to the assessment Spitzer WO, Leblanc FE, Dupuis M. Scientific approach to the assessment
and management of activity-related spinal disorders. Spine 1987;7 and managem

6 Koes BW, Bouter LM, Beckerman H, van der Heijden GJMG, Knipschild PG. Physiotherapy exercises and back pain: a blinded review. $B M J$ 1991;302:1572-6.

7 Koes BW, Assendelft WJJ, van der Heijden GJMG, Bouter LM, Knipschild PG. Spinal manipulation and mobilisation for back and neck complaints: blinded review. BMF 1991;303:1298-303.

8 Bergquist-Ullman $M$, Larsson $M$. Acute low back pain in industry: controlled prospective study with special reference to therapy and confounding factors. Acta Orthop Scand 1977;170 (suppl):11-117.

9 Meade TW, Dyer S, Browne W, Townsend J, Frank AO. Low back pain of mechanical origin: randomised comparison of chiropractic and hospital outpatient treatment. BMF 1990;300:1431-7.

10 Sims-Williams H, Jayson MIV, Young SMS, Baddeley H, Collins E. Controlled trial of mobilisation and manipulation for low back pain: hospital patients. BMF 1979;ii:1318-20.

11 Doran DML, Newell DJ. Manipulation in treatment of low back pain: multicentre study. BMF 1975; ii:161-4.

12 Coxhead CE, Inskip H, Meade TW, North WRS, Troup JDG. Multicentre trial of physiotherapy in the management of sciatic symptoms. Lancet $1981 ; \mathrm{i}: 1065-8$

13 Sims-Williams H, Jayson MIV, Young SMS, Baddeley H, Collins E. Controlled trial of mobilisation and manipulation for patients with low back pain in general practice. $B M \mathcal{F} 1978$;ii:1338-40.

14 Siehl D, Olson DR, Ross HE, Rockwood EE. Manipulation of the lumbar spine with the patient under general anaesthesia: evaluation by electromyography and clinical-neurologic examination of its use for lumbar nerve root compression sydrome. $\mathcal{F}$ Am Osteopath Assoc 1971;70:433-50.

15 Koes BW, Bouter LM, Knipschild PG, van Mameren H, Essers AHM Houben JP, et al. The effectiveness of manual therapy, physiotherapy and continued treatment by the general practitioner for non-specific back and neck complaints: design of a randomized clinical trial. $f$ Manipulative neck complaints: design
Physiol Ther (in press.)

16 Koes BW, Bouter LM, van Mameren H, Essers AHM, Verstegen GMJR, Hofhuizen DM, et al. The effectiveness of manual therapy, physiotherapy and treatment by the general practitioner for non-specific back and neck and treatment by the general practitioner for non-spe

17 Koes BW, Bouter LM, van Mameren H, Essers AHM, Verstegen GMJR, Hofhuizen DM, et al. A blinded randomized clinical trial of manual therapy and physiotherapy for chronic back and neck complaints: physical outcom measures. $\mathcal{F}$ Manipulative Physiol Ther (in press).

18 Dixon WJ, Brown MB, Engelman L, Jenrich RI. BMDP statistical softwar manual. Berkeley: University of California Press, 1990.

(Accepted 4 December 1991)

\section{Appendix}

We calculated the power of the study based on the primary outcome measure (severity of the main complaint measured on a 10 point scale) after 12 months' follow up. We used the following sample size equation:

$$
\mathrm{n}=\sqrt{\frac{2(Z \alpha+Z \beta)^{2} \times 2 \sigma_{\Delta}^{2}}{\Delta}}
$$

$\mathrm{n}=$ The number of participants after correction for loss to follow up (50 participants in each study group after 12 months' follow up).

$\Delta=$ The minimal difference in improvement score between the two study groups that was considered to be of clinical relevance. This was set at 1 point $(\Delta=1)$

$Z \alpha=$ The variable of the standard normal distribution corresponding with a significance level of $5 \%$, two sided test.

$\sigma_{\Delta}=$ the variance of the difference scores (score at baseline minus score after 12 months' follow up) was estimated to be the square of $2 \cdot 25$ (derived from table IV).

$Z \beta=$ The parameter to be calculated.

The calculation shows that the power of the study to detect a difference in improvement scores of 1 point is $60 \%$. 